\title{
The Status of Interdisciplinary Education in Advanced Education Programs at U.S. Dental Schools
}

\author{
Vidya Ramaswamy, Nadeem Karimbux, Irina F. Dragan, Noshir R. Mehta, \\ Theodora Danciu
}

Abstract: Interdisciplinary education (IDE) during dental residencies can help produce dentists who work more efficiently to provide continuous and reliable patient care. The aim of this study was to assess the extent and type of interdisciplinary education in dental residency programs at U.S. dental schools. A 24-item survey addressing didactic courses and patient care was sent to academic and/or clinical deans at 65 U.S. dental schools in fall 2016; they were asked to forward the survey to the appropriate person in their school. The questions addressed IDE characteristics such as the academic home for IDE, focus areas, defined outcomes, program objectives, and perceived institutional barriers. Of the 65 schools invited to participate, 31 responded to the survey for an overall response rate of 48\%. Of those schools, 23 (74\%) reported having IDE for their advanced/postgraduate students. Among the schools with IDE, their IDE learning experiences primarily involved residents in different disciplines participating in clinical case group projects and small group workshops, and 77\% of IDE faculty taught in department-specific clinical spaces as opposed to teaching together in a single clinic. The respondents identified barriers to implementing IDE such as a lack of clearly defined competencies, logistical challenges including academic calendars and scheduling, and faculty resistance. Also, 43\% reported that their institutions did not have a program to support IDE faculty development. At the time of this survey, most of the respondents did not have a clearly defined IDE model consisting of competencies, defined assessments, and milestones.

\begin{abstract}
Vidya Ramaswamy is Associate Director for Curriculum and Program Evaluation, University of Michigan School of Dentistry; Nadeem Karimbux is Academic Dean and Professor, Tufts University School of Dental Medicine; Irina F. Dragan is Assistant Professor, Tufts University School of Dental Medicine; Noshir R. Mehta is Professor of Public Health and Community Service, Tufts University School of Dental Medicine; and Theodora Danciu is Clinical Associate Professor, University of Michigan School of Dentistry. Direct correspondence to Dr. Irina Dragan, Tufts University School of Dental Medicine, One Kneeland Street, Boston, MA 02111; 347-249-1729; irina.dragan@tufts.edu.
\end{abstract}

Keywords: advanced dental education, postgraduate dental education, dental residents, interdisciplinary education, curriculum

Submitted for publication 8/30/17; accepted 3/16/18

doi: $10.21815 / J D E .018 .126$

$\mathrm{T}$ The importance of collaborative education is reflected in recommendations of the Institute of Medicine (IOM) that all health care clinicians should be able to "cooperate, collaborate, communicate, and integrate care in teams to ensure that care is continuous and reliable" and the results of previous studies. ${ }^{1-6}$ Interdisciplinary teamwork is coordinated care among practitioners of different disciplines, resulting in an interaction that generates new knowledge, methods, or perspectives. ${ }^{7}$ Nancarrow et al. used the term "interdisciplinary" to refer to all members of a health care team (professional and nonprofessional staff members) and used the term "interprofessional" for teams consisting exclusively of professionals from different professions or disciplines. ${ }^{8}$ Some studies in dentistry have used the term "interdisciplinary" to describe collaboration among members of different specialties. ${ }^{9-14}$ In this study, we used the term "interdisciplinary education" (IDE) to refer to training and patient care that takes a multidental specialty approach-encompassing different dental specialties regardless of American Dental Association (ADA) recognition, in which residents learn with, from, and about one another.

A collaborative education model would meet the needs of the $21^{\text {st }}$ century health care system in several ways. First, such education allows for training that fully captures the day-to-day activities needed for continuous and timely delivery of quality patient care, as opposed to "siloed" training, treatment planning, and patient management. ${ }^{2-6} \mathrm{By}$ placing the interests of patients at the center of health care delivery, this model also encourages providers to be sensitive to cultural diversity and to reflect 
on the impact of individual differences on health care outcomes. Second, such a model encourages the development of communication skills not only with team members but also with patients and their families to optimize treatment outcomes. Third, by training in collaborative teams, residents learn what it means to be a good team player, working with others to reduce gaps, redundancies, and errors in treatment. Fourth, in 1983, Hursh and Moore argued that, by combining inputs from various disciplines, learners can challenge conclusions and work toward a more comprehensive understanding of a given problem. ${ }^{6}$ According to those researchers, a collaborative education model providing learners with exposure to interactions, concepts, or problems from different perspectives may support essential cognitive development, allowing not only for knowledge acquisition but also for learner-driven development of organizing schemes and application of those schemes to new clinical scenarios. Such a collaborative model needs to be reinforced in graduate residency programs through adequate training of residents in collaborative interdisciplinary care.

In dental specialty programs, learning how to design evidence-based treatment plans and deliver patient care in interdisciplinary teams is the logical first step towards interprofessional collaboration, an essential model for health care. Trainees need to be part of teams in which assumptions and tools specific to various dental specialties are applied to comprehensive patient care. An interdisciplinary model also requires active learner participation to be successful. Without the constant requirement "to think, challenge, infer, and synthesize disparate elements of information," learners will likely not be able to integrate the material. This requirement implies that advanced dental education programs need to have a component in which residents plan and execute patient care in interdisciplinary teams, as well as participate in classroom activities that will prepare them for this model. The accreditation standards for prosthodontics, for example, require that residents "receive instruction in diagnosis and treatment planning as a member of interdisciplinary teams in order to develop, implement, and assess treatment approaches that optimize therapeutic outcomes." 15 These requirements support the development of an IDE framework that includes competencies and milestones for assessment.

Our search of the literature found no publications defining the specific education and training dental residents should receive to function effectively in interdisciplinary teams; this absence mirrors the gap others have reported in the literature on interprofessional education. ${ }^{16,17}$ This gap extends to what evaluation tools are optimal to assess collaborative team dynamics and interactions. ${ }^{18,19}$ To support learner development, IDE should be taught in rigorous programs with well-defined competencies. As a first step toward filling this gap, the aim of this study was to assess the extent and type of interdisciplinary education in dental residency programs at U.S. dental schools.

\section{Methods}

This study was classified as exempt from oversight by the University of Michigan Institutional Review Board (Study eResearch ID: HUM00117292). For the study, we designed a 24-item survey based on templates for interprofessional education at U.S. dental and medical schools. ${ }^{20,21}$ On our survey, IDE was defined as a model in which residents learn with, from, and about one another for purposes of enhancing collaboration among dental specialties, regardless of ADA recognition. The designated specialties were periodontics, prosthodontics, endodontics, orthodontics, oral and maxillofacial pathology/ radiology/surgery, orofacial pain, oral medicine, and restorative dentistry.

We considered that students in advanced/ postgraduate dental education programs may take courses and treat patients in various IDE settings. For the learning component of the survey, three sections were defined for the IDE settings: didactic basic science courses (any basic science courses that students in different specialties take together, e.g., oral biology, pharmacology); didactic clinic science courses (any clinical science courses that students in different specialties take together, e.g., implant dentistry); and clinical care (any scenario in which students in different specialties treat patients together, meaning they treatment plan together and complete treatment according to the phases of the treatment plan). A programmatic section consisted of eight questions on components of the IDE program, including the nature of IDE experiences, expected outcomes, defined competencies, program support, and others. Prior to its distribution, the survey was reviewed by the program directors for periodontology and graduate restorative dentistry, senior associate dean, and associate dean for patient services at the University of Michigan School of Dentistry and the 
program director and chair of endodontics and the assistant dean for postgraduate clinical education at Tufts University School of Dental Medicine.

Invitations to participate were emailed to the associate deans for academic and/or clinical affairs at 65 U.S. dental schools in the fall of 2016, using their contact information in the American Dental Education Association (ADEA) Directory of Institutional Members and Association Officers (www. adea.org/publications/DIM.aspx). Recipients were asked to identify their position and the name of their institution. They were also asked if their school offered dental residency programs and were requested, if applicable, to forward the email to persons who were better positioned to complete the survey such as the chair of the postgraduate certificate and residency program committee, director of postgraduate education, or associate dean for postgraduate affairs. Further, recipients were asked if their programs used IDE for didactic basic science courses and/or clinical courses and/or treatment/case of cases.

Qualtrix software was used for the online survey and data analysis. The invitation message included a URL to a password-protected site for accessing the survey. The original timeline for response was approximately two weeks, and one subsequent email was sent to representatives of the schools that did not respond. The total elapsed timeline from the first invitation to respond to the survey to the closure of responses was approximately four weeks.

\section{Results}

Of the 65 schools invited to participate, representatives of 33 responded. However, two of those were eliminated as duplicate responses from the same institution, so the overall response rate for the survey was $48 \%(n=31)$. Eight of the 31 respondents reported they had no IDE program at their institution. The 23 respondents with IDE programs were primarily deans, associate deans, or assistant deans. Respondents skipped some survey items, so we report the number who responded to each question. Institutions whose representatives identified themselves were the University of California, San Francisco, University of Tennessee, Nova Southeastern University, University of Washington, Texas A\&M University, University of California, Los Angeles, University of Oklahoma, University of Michigan, Tufts University, University of Connecticut, University of Detroit Mercy, New
York University, Loma Linda University, Ohio State University, Boston University, University of Minnesota, University of Iowa, and University of Texas at San Antonio.

Respondents identified graduate program directors as the main coordinators for IDE activity $(74 \%$, $\mathrm{n}=17$ ). The percentage of respondents who rated the various leadership positions as very important or extremely important for IDE were as follows: program director $(96 \%, \mathrm{n}=22)$, division head $(58 \%$, $\mathrm{n}=11)$, chair $(48 \%, \mathrm{n}=11)$, and dean $(43 \%, \mathrm{n}=10)$. A majority of respondents $(90 \%, n=19)$ reported that their IDE program was a required part of their academic program $(n=21)$ with about $44 \%(n=10)$ reporting "advanced and graduate education" and $30 \%(n=7)$ "Office of Academic Affairs" as the home of IDE education.

When asked how important developing IDE competence was in their clinical program, out of 14 who responded to this question, seven $(50 \%)$ rated it as important, and five (36\%) as very important. Table 1 lists the IDE outcomes identified by participants. The top three outcomes of IDE identified by more than $80 \%$ of those respondents were more efficient treatment, team-building skills, and improved treatment outcomes.

The dominant type of IDE learning experiences was some residents from different disciplines participating in clinical case group projects and small group workshops (Table 2). Out of 13 who responded to a question about how faculty members teach IDE in their clinics, a majority $(77 \%, n=10)$ said that they teach in separate department-specific clinical spaces. The dominant mode of participation in basic and clinical sciences courses was in the form

Table 1. Expected outcomes of interdisciplinary programs, by percentage and number of total respondents with interdisciplinary programs $(\mathrm{N}=23)$

\begin{tabular}{lc} 
Outcome & Percentage (N) \\
\hline More efficient patient treatment & $96 \%(22)$ \\
Team-building skills & $83 \%(19)$ \\
Improved treatment outcomes & $83 \%(19)$ \\
Reduction in patient complaints & $48 \%(11)$ \\
Other & $13 \%(3)$
\end{tabular}

Note: "Other" responses were "learn about each other's professions and respect for each other's knowledge base"; "residents gain knowledge of other specialty treatment techniques, thus increasing their overall knowledge level"; and "residents learn interdisciplinary communication skills that will help them in future practice." 
Table 2. Interdisciplinary experiences offered, by number and percentage of total respondents with interdisciplinary education (IDE) programs $(\mathrm{N}=23)$

\begin{tabular}{|c|c|}
\hline Experience & Number (\%) \\
\hline $\begin{array}{l}\text { Residents from all disciplines participate in } \\
\text { a clinical case group project }\end{array}$ & $12(52 \%)$ \\
\hline $\begin{array}{l}\text { Residents from different disciplines participate } \\
\text { in small group workshops }\end{array}$ & $11(48 \%)$ \\
\hline $\begin{array}{l}\text { The outcome of IDE care is measured at the } \\
\text { completion of each case }\end{array}$ & $8(35 \%)$ \\
\hline $\begin{array}{l}\text { Residents from different disciplines are asked } \\
\text { to complete peer evaluation forms }\end{array}$ & $4(17 \%)$ \\
\hline Objective structured clinical examination (OSCE) & $3(13 \%)$ \\
\hline $\begin{array}{l}\text { Residents from different disciplines participate } \\
\text { in a reflective writing piece }\end{array}$ & $2(9 \%)$ \\
\hline $\begin{array}{l}\text { Residents from different disciplines have to take } \\
\text { an interdisciplinary case-based written exam }\end{array}$ & $2(9 \%)$ \\
\hline $\begin{array}{l}\text { A patient survey is used to assess inter- } \\
\text { disciplinary care }\end{array}$ & $2(9 \%)$ \\
\hline $\begin{array}{l}\text { Residents from different disciplines have to take } \\
\text { an interdisciplinary case-based oral exam }\end{array}$ & $1(4 \%)$ \\
\hline Not assessed at this time & $5(22 \%)$ \\
\hline Other, please specify & $4(17 \%)$ \\
\hline \multicolumn{2}{|c|}{$\begin{array}{l}\text { Note: Respondents were asked to select all that applied. } \\
\text { "Other" responses were "These are selective courses and do } \\
\text { not apply to all"; "Not inclusive of all programs"; "Residents } \\
\text { present interdisciplinary cases in a ground rounds venue; } \\
\text { residents provide interdisciplinary treatment in a clinic setting } \\
\text { and are assessed by their faculty"; and "Residents present } \\
\text { cases to an interdisciplinary audience, including faculty } \\
\text { members from appropriate disciplines." }\end{array}$} \\
\hline
\end{tabular}

of some residents participating in some courses, with $80 \%$ selecting this option for basic sciences and $77 \%$ selecting this option for clinical sciences (Table 3). In these programs, interdisciplinary participation was highest in basic science courses $(n=21,91 \%)$ as compared to clinical science courses $(n=14,61 \%)$, treatment planning seminars $(\mathrm{n}=13,57 \%)$, or delivering interdisciplinary patient care $(n=14,61 \%)$. First-year residents were reported to participate the most in IDE experiences (Table 4).

The survey also identified some challenges and barriers to implementing IDE. When asked if their program had clearly defined competencies, of the 22 respondents, six $(27 \%)$ said yes, five $(23 \%)$ said maybe, and $11(50 \%)$ said no. Out of 14 who responded to the question about how prepared their residents were for IDE, four (17\%) said not prepared, nine $(64 \%)$ rated them as somewhat prepared, and only one $(7 \%)$ rated them as very prepared. Table 5 lists some of the barriers to implementing IDE, such as academic calendars and scheduling, faculty resistance, and not having integrated treatment units. Approximately $43 \%$ of the respondents said they did not have a program at their institution to support faculty development on this topic.

Table 3. Extent of participation of residents in basic science and clinical science courses, by percentage and number of total basic science/clinical science courses

\section{Extent of Participation}

Basic Science Clinical Science

All residents from all advanced/postgraduate programs participate in all these courses.

Some residents from some advanced/postgraduate programs participate in some of these courses.

Some residents from each specialty participate in these department-specific courses with no other specialty students present.

Residents do not take any of these courses.

Courses $(n=20)$ Courses $(n=13)$

Note: Respondents were asked to select all that applied.

$\begin{array}{cc}20 \%(4) & 23 \%(3) \\ 80 \%(16) & 77 \%(10) \\ 25 \%(5) & 23 \%(3)\end{array}$

0

Table 4. Residents' interdisciplinary participation across years of study, by type of course

\begin{tabular}{lcccc} 
Year & $\begin{array}{c}\text { Basic Sciences } \\
(\mathrm{N}=21)\end{array}$ & $\begin{array}{c}\text { Clinical Sciences } \\
(\mathrm{N}=13)\end{array}$ & $\begin{array}{c}\text { Interdisciplinary Treatment } \\
\text { Planning Seminar }(\mathrm{N}=13)\end{array}$ & $\begin{array}{c}\text { Interdisciplinary Treatment } \\
\text { Rendered (N=13) }\end{array}$ \\
\hline First year & $21(100 \%)$ & $13(100 \%)$ & $12(92 \%)$ & $9(69 \%)$ \\
Second year & $12(57 \%)$ & $10(77 \%)$ & $11(85 \%)$ & $11(85 \%)$ \\
Third year & $4(19 \%)$ & $10(77 \%)$ & $12(92 \%)$ & $13(100 \%)$ \\
Fourth year & $1(5 \%)$ & 0 & $2(15 \%)$ & $4(31 \%)$
\end{tabular}

Note: Since individual residency programs range from one to four years depending on discipline and program curricula, the smaller numbers in years after the first may have been a result of having fewer residents in those years. 
Table 5. Respondents' perceptions of severity of barriers to implementation of interdisciplinary education $(\mathrm{N}=23)$

\begin{tabular}{lc} 
Barrier & Mean (SD) \\
\hline Academic calendars and schedule & $50.27(34.52)$ \\
Faculty resistance & $42.85(29.73)$ \\
Separate patient treatment areas not in & $40.47(34.74)$ \\
$\quad$ proximity to one another & \\
Lack of institutional support & $37.53(27.34)$ \\
Lack of student interest & $36.71(27.11)$ \\
Lack of classroom space & $24.59(28.85)$ \\
Comparable readiness of students & $24.05(19.68)$
\end{tabular}

Note: Responses were on scale from $0=$ no barrier to $100=$ major barrier.

\section{Discussion}

With our survey, we sought to identify the scope and types of IDE in advanced and postgraduate programs in U.S. dental schools. Although the respondents agreed it was important to develop IDE competencies, that attitude was not supported by adequate IDE experiences that focused on delivering patient care or by the scope of participation, with some residents participating in only some courses. Moreover, a major challenge was the lack of clarity in how IDE competencies were defined. While $86 \%$ of the respondents agreed that the development of IDE competencies was important or very important, $50 \%$ reported that these competencies were not clearly defined.

This survey's results suggest that IDE education in the responding dental school-based programs was primarily in the form of some residents from different disciplines coming together sometimes for clinical case projects or group work. Faculty instructors appeared to teach in separate clinical spaces that did not promote integration. These practices reinforce "siloed" dental training in postgraduate education. The training may also be lacking in depth and coverage. IDE participation was reportedly higher in basic sciences courses than in clinical courses, treatment planning, or patient care. Participation in IDE was reported to be highest in the first year of residencies and dropped to almost none in the fourth year. Given that the respondents did not rate their incoming residents highly on their level of preparedness for IDE, training experiences during the residencies did not seem sufficient to address the gap.

The respondents also identified potential challenges to IDE development and sustainability.
The top barrier was academic calendar/scheduling challenges. In a study of interprofessional education at U.S. dental schools, Palatta et al. suggested that coordination of schedules needed to be implemented to transform non-collaborative care models. ${ }^{20}$ For effective implementation of IDE, it is necessary to create opportunities for IDE in advanced/postgraduate dental curricula and also to train faculty to teach and assess IDE learning.

A framework that can help formulate an efficient IDE program is that of Entrustable Professional Activities (EPAs). ${ }^{22-24}$ In the EPA framework, skills, knowledge, and attitudes that are learner-centric (ability to interpret a radiograph, ability to classify a patient's periodontal disease status) are linked to the quality of the work performed (appropriate treatment plan). ${ }^{22}$ EPAs do not substitute for competencies, but group competencies into professional activities required on a daily basis.

Our findings also suggest the need for faculty development. Similarly, a study of 16 medical schools found that faculty development was needed to train faculty for shared didactic instruction and to teach using the team-based learning and simulation that are the most conducive to teaching in interdisciplinary teams..$^{25}$ The EPA framework can also impact faculty development (identified as a barrier in our survey) by involving faculty in entrustment decisions and facilitating a strong understanding of competencybased education in assessment of students.

This study had a number of limitations. A 48\% overall response rate is not sufficient to generalize the results to the non-responding schools; also, response rates on individual items were lower. However, survey respondents represented public and private institutions in diverse geographic locations. Some of the low response rates on individual questions may have been due to the lack of rigorous IDE programs. Another limitation is that the survey was distributed to associate deans for academic and/or clinical affairs, who may not have as much knowledge to accurately answer the questions as would program directors. We encouraged the recipients to forward the survey to persons most knowledgeable with IDE at their institution. We know this was done in some institutions as we had responses from the chair of the postgraduate certificate and residency program committee and the director of graduate education and associate dean for postgraduate affairs. Future researchers on this topic should contact program directors directly. 
Another important limitation is that, because of the survey distribution method selected, none of the many advanced/postgraduate programs at institutions other than dental schools were invited to participate, thus missing the opportunity to assess IDE across advanced dental education. Future research should include those programs to provide a more complete picture of IDE in advanced dental education. Finally, a qualitative analysis of IDE based on focus group discussions may have yielded more informative data regarding challenges surrounding IDE implementation. This study provided preliminary data to justify a follow-up qualitative analysis. Despite these limitations, our study provided some initial information about IDE implementation in residency programs at dental schools.

\section{Conclusion}

Addressing the needs of the $21^{\text {st }}$ century health care system requires all clinicians to function efficiently in a collaborative care model. In advanced dental education, the first step for this is an interdisciplinary framework. However, at the time of this survey, most of the dental school-based programs participating in our study did not have a clearly defined IDE model consisting of competencies, defined assessments, and milestones. The majority of the responding programs reported IDE efforts that consisted of participating in basic and clinical science courses, with a minority of respondents reporting that their residents delivered patient care as part of an interdisciplinary team. The side-by-side education of students in a classroom setting should be extended to meaningful interactions among residents that can be evaluated. Furthermore, for an IDE model to be successful, there needs to be significant faculty development, which seemed to be lacking at most institutions. Faculty need training to facilitate teaching in teams as well as in pedagogy suited to IDE such as team-based learning. Future research should collect information that can be used to develop competency-based IDE curricula to assist programs in training residents in IDE.

\section{Acknowledgments}

This study would not have been possible without the input of all survey participants, for which the authors extend their thanks. This study was funded in part by the Roy H. Roberts Award. The authors would like to thank Dr. Carol Anne Murdoch-Kinch and Dr. Robert Amato for their comments and suggestions.

\section{Disclosure}

The authors did not report any conflicts of interest that may have influenced the design, execution, or presentation of this scholarly work.

\section{REFERENCES}

1. Greiger AC, ed. Health professions education: a bridge to quality. An Institute of Medicine report. Washington, DC: National Academy Press, 2003.

2. Frank JR, Snell LS, Cate OT, et al. Competency-based medical education: theory to practice. Med Teach 2010; 32(8):638-45.

3. Ten Cate O, Scheele F. Competency-based postgraduate training: can we bridge the gap between theory and clinical practice? Acad Med 2007;82(6):542-7.

4. Chen HC, van den Broek WE, Ten Cate O. The case for use of entrustable professional activities in undergraduate medical education. Acad Med 2015;90(4):431-6.

5. Brooks MA. Medical education and the tyranny of competency. Perspect Biol Med 2009;52(1):90-102.

6. Hursh BHP, Moore M. An interdisciplinary model to implement general education. J Higher Educ 1983;54(1): 42-9.

7. Choi BC, Pak AW. Multidisciplinarity, interdisciplinarity, and transdisciplinarity in health research, services, education, and policy: 1. Definitions, objectives, and evidence of effectiveness. Clin Invest Med 2006;29(6):351-64.

8. Nancarrow SA, Booth A, Ariss S, et al. Ten principles of good interdisciplinary teamwork. Hum Resour Health 2013;11:19.

9. Almog DM, Meitner SW, Even-Hen N, et al. Use of interdisciplinary team approach in establishing esthetic restorative dentistry. N Y State Dent J 2005;71(5):44-7.

10. Hobson RS, Carter NE, Gillgrass TJ, et al. The interdisciplinary management of hypodontia: the relationship between an interdisciplinary team and the general dental practitioner. Br Dent J 2003;194(9):479-82.

11. McGuire MK. 2001 interdisciplinary care conference: five disciplines, one focus. Am J Orthod Dentofacial Orthop 2001;120(3):232-4.

12. Lyons KM, Darby I. Interdisciplinary periodontics: the multidisciplinary approach to the planning and treatment of complex cases. Periodontol 2000 2017;74(1):7-10.

13. Moskona D, Kaplan I, Leibovich P, et al. A three-year programme in oral diagnosis and treatment planning: a model using an interdisciplinary teaching team. Eur $\mathrm{J}$ Dent Educ 1999;3(1):27-30.

14. Ramesh A, Ganguly R, Qualters DM. An interdisciplinary, team-based design for an oral and maxillofacial radiology course for postdoctoral dental students. J Dent Educ 2014;78(9):1339-45.

15. Commission on Dental Accreditation. Self-study guide for the evaluation of a prosthodontics education program. At: www.ada.org/ /media/CODA/Files/spec_prostho_ssg. doc?la=en2016. Accessed 30 Aug. 2017. 
16. Lutfiyya MN, Brandt BF, Cerra F. Reflections from the intersection of health professions education and clinical practice: the state of the science of interprofessional education and collaborative practice. Acad Med 2016;91(6):766-71.

17. Reeves S, Perrier L, Goldman J, et al. Interprofessional education: effects on professional practice and health care outcomes (update). Cochrane Database Syst Rev 2013(3):CD002213.

18. Salas E, DiazGranados D, Klein C, et al. Does team training improve team performance? A meta-analysis. Hum Factors 2008;50(6):903-33.

19. Salas E, Rosen MA. Building high reliability teams: progress and some reflections on teamwork training. BMJ Qual Saf 2013;22(5):369-73.

20. Palatta A, Cook BJ, Anderson EL, Valachovic RW. 20 years beyond the crossroads: the path to interprofessional education at U.S. dental schools. J Dent Educ 2015;79(8):982-96.
21. Blue AV, Zoller J, Stratton TD, et al. Interprofessional education in U.S. medical schools. J Interprof Care 2010;24(2):204-6.

22. Ten Cate O. Entrustment decisions: bringing the patient into the assessment equation. Acad Med 2017;92(6): 736-8.

23. Carraccio C, Burke AE. Beyond competencies and milestones: adding meaning through context. J Grad Med Educ 2010;2(3):419-22.

24. Ten Cate O, Scheele F. Competency-based postgraduate training: can we bridge the gap between theory and clinical practice? Acad Med 2007;82(6):542-7.

25. West C, Graham L, Palmer RT, et al. Implementation of interprofessional education (IPE) in 16 U.S. medical schools: common practices, barriers, and facilitators. J Interprof Educ Pract 2016;4:41-9. 